\title{
Atitudes e Práticas face à Exposição Solar dos Carteiros do Município de Juazeiro do Norte-CE
}

\author{
Attitudes and Practices towards the Solar Exhibition of the Postmen of the Municipality of Juazeiro do Norte-CE \\ Actitudes y Prácticas frente a la Exposición Solar de Carteros en el Municipio de Juazeiro do Norte-CE
}

\begin{abstract}
RESUMO
As doenças relacionadas ao trabalho podem ser enquadradas como Problema de Saúde Pública (PSB), pois acometem um importante número de indivíduos e são passíveis de se tornarem objeto de ações individuais ou coletivas para sua prevenção e controle em termos populacionais. OBJETIVO: Analisar as atitudes e práticas face à exposição solar dos carteiros do Município de Juazeiro do Norte-CE. MÉTODO: Estudo de coorte transversal com enfoque na abordagem quantitativa. RESULTADOS: Os carteiro se expoem ao sol em horários indevidos e que a maioria dos entrevistados fazem exposição ao sol por volta das 13:00 às 17:00 horas, período do dia que as radiações UVA e UVB estão mais incidentes. CONCLUSÃO: Constatamos que os carteiros da cidade do Juazeiro do Norte- CE constituem um grupo susceptível a doenças de pele, a exemplo do câncer de pele, pois na sua maioria, em relação ao fototipo cutâneo, foram avaliados como possuidores de peles do Tipo II e III.
\end{abstract}

DESCRITORES: Saúde Pública; Neoplasias Cutâneas; Dermatologia.

\section{ABSTRACT}

Work-related diseases can be classified as a Public Health Problem (PSB), as they affect an important number of individuals and are liable to become the object of individual or collective actions for their prevention and control in population terms. OBJECTIVE: To analyze the attitudes and practices towards the sun exposure of postmen in the Municipality of Juazeiro do Norte-CE. METHOD: Cross-sectional cohort study focusing on the quantitative approach. RESULTS: Postmen expose themselves to the sun at inappropriate times and that most of the interviewees expose themselves to the sun around 1:00 pm to 5:00 pm, the period of the day when UVA and UVB radiation are most prevalent. CONCLUSION: We found that postmen from the city of Juazeiro do Norte-CE constitute a group susceptible to skin diseases, such as skin cancer, since most of them, in relation to the skin phototype, were evaluated as having Type II skins. and III.

DESCRIPTORS: Public health; Skin Neoplasms; Dermatology.

\section{RESUMEN}

Las enfermedades relacionadas con el trabajo se pueden catalogar como Problema de Salud Pública (PSB), ya que afectan a un número importante de personas y pueden convertirse en objeto de acciones individuales o colectivas para su prevención y control en términos poblacionales. OBJETIVO: Analizar las actitudes y prácticas frente a la exposición solar de carteros del Municipio de Juazeiro do Norte-CE. MÉTODO: Estudio de cohorte transversal con enfoque cuantitativo. RESULTADOS: Los carteros se exponen al sol en momentos inapropiados y que la mayoría de los entrevistados se exponen al sol alrededor de las 13:00 a las 17:00 horas, período del día en que las radiaciones UVA y UVB son más incidentes. CONCLUSIÓN: Encontramos que los carteros de la ciudad de Juazeiro do Norte-CE constituyen un grupo susceptible a enfermedades de la piel, como el cáncer de piel, ya que la mayoría de ellos, en relación al fototipo cutáneo, fueron evaluados con pieles Tipo II. y III.

DESCRIPTORES: Salud Pública; Neoplasias cutáneas; Dermatología.

RECEBIDO EM: 28/07/2020 APROVADO EM: 08/09/2020

\section{Séphora Natércia Albuquerque Oliveira}

Médica, Mestre em Medicina Preventiva pela Universidade Federal de São Paulo - UNIFESP.

ORCID: 0000-0002-1381-7453 


\section{Modesto Leite Rolim Neto}

Professor Livre Docente pela Faculdade de Saúde Pública da USP. Pós-Doutor em Saúde Pública pela Universidade de São Paulo - USP.

ORCID: 0000-0002-7715-5508

\section{Francisco Antônio Castro Lacaz}

Médico, Mestre em Medicina, área de Medicina Preventiva, pela Faculdade de Medicina de São Paulo da Universidade de São Paulo; Doutor em Medicina, área de Saúde Coletiva pela Faculdade de Ciências Médicas da Universidade Estadual de Campinas; ós-Doutor em Psicologia Social pela Universidade Autônoma de Barcelona. Atualmente é Professor Titular (aposentado) da Escola Paulista de Medicina da Universidade Federal de São Paulo, Departamento de Medicina Preventiva. Docente colaborador do Programa de Pós-Graduação em Saúde Coletiva (mestrado), Setor de Ciências da Saúde da Universidade Federal do Paraná (UFPr).

ORCID: 0000-0001-7621-3756

\section{INTRODUÇÃO}

A organização das ações em saúde dos trabalhadores na rede de serviços de saúde do Sistema Único de Saúde (SUS) constitui um processo sociopolítico e técnico ainda em construção, a partir de alianças solidárias entre sindicatos de trabalhadores e técnicos dos serviços públicos de saúde, de hospitais universitários, da fiscalização do Trabalho e da Previdência Social, conformando os Programas de Saúde do Trabalhador (PST) ${ }^{[1]}$.

Mais recentemente com a contribuição das Ciências Sociais em Saúde, da Saúde Pública, Saúde Coletiva e da Medicina Social para entender a relação dos conhecimentos entre Trabalho e Saúde, constitui-se um novo campo chamado Saúde do Trabalhador $(S T)^{[2]}$. As ações de saúde do trabalhador tiveram as suas raízes no processo histórico das lutas sociais deflagradas no Brasil a partir da década de 1970, mas tais ações começaram a ganhar corpo apenas no final da década de 1980 nos governos municipais como parte de uma política com participação democrática ${ }^{[3]}$.

Lacaz $^{[2]}$ define Saúde do Trabalhador - ST como o campo de práticas e conhecimentos cujo enfoque teórico-metodológico, no Brasil, emerge da Saúde Coletiva, buscando conhecer (e intervir) (n)as relações trabalho e saúde-doença, tendo como referência central o surgimento de um novo autor social: a classe operária industrial.

A ST, de acordo com o artigo $6^{\circ}$ da Lei $\mathrm{n}^{\circ} 8.080 / 90$, é um conjunto de atividades que se destina, através de ações de vigilância epidemiológica e sanitária, à promoção e proteção dos trabalhadores, assim como à recuperação e reabilitação da saúde dos trabalhadores submetidos aos riscos e agravos advindos das condições de trabalho consideradas como atribuições do SUS ${ }^{[1-5]}$.

Neste enquadre situacional, os ambientes e os processos de trabalho relacionamse aos hoje chamados acidentes e doenças relacionadas ao trabalho. As doenças relacionadas ao trabalho podem ser enquadradas como Problema de Saúde Pública (PSB), pois são problemas que acometem um importante número de indivíduos e são passíveis de se tornarem objeto de ações individuais ou coletivas para sua prevenção e controle em termos populacionais ${ }^{[3-6]}$.

Nessa perspectiva, evidenciando a importância epidemiológica para o câncer de pele, o Instituto Nacional do Câncer (INCA $)^{[12]}$ afirma que o não melanoma é o câncer mais freqüente no Brasil correspondendo a $25 \%$ de todos os tumores malignos registrados no país onde estima-se a ocorrência de 113.850 para o ano de 2010, sendo 53.410 homens e 60.440 mulheres. Embora o câncer de pele seja o mais freqüente no Brasil o melanoma representa apenas $4 \%$ das neoplasias malignas do tegumento, apesar de ser o mais grave devido à sua alta possibilidade de metástase. Para o ano de 2010, estima-se a ocorrência de 5.930 novos caos, sendo 2960 homens e 2.970 mulheres ${ }^{[4]}$. Podemos citar dentre as populaçóes de trabalhadores que estão mais susceptíveis a ter doenças de pele, os pescadores, jardineiros, lavradores, carteiros, entre outros; por serem profissionais que enfrentam uma intensa jornada de trabalho com longos períodos de exposição solar.
Tal medida é especialmente importante, considerando que, a ação educativa deve ser priorizada entre as diversas estratégias de controle do câncer da pele, estratégias estas que incluem o aconselhamento quanto à exposição solar ${ }^{[3-7]}$.

Neste contexto, o problema foi delineado a partir dos carteiros da cidade do Juazeiro do Norte, no intuito de detectar as condições de trabalho e ocorrência dos fatores de risco para os agravos à saúde relacionada ao trabalho e como proposta de intervenção a médio e longo prazo, no sentido de orientar mudanças nas formas de atuação destes trabalhadores.

\section{MÉTODO}

\section{TIPO DE ESTUDO}

A fim de analisar as atitudes e práticas de proteção/exposição ao sol dos carteiros do Município de Juazeiro do Norte-CE, realizamos um estudo de coorte transversal com um enfoque de abordagem quantitativa, no limete temporal de 2009 a 2017. A opção pelo delineamento transversal encontra respaldo nas consideraçôes de Hulley et al.,, ${ }^{[6]}$ que consideram os estudos transversais como fonte importante de informação sobre a saúde e os hábitos de uma população, no momento em que o estudo é realizado, fornecendo estimativas tais como a prevalência de determinada situação ou comportamento associado à saúde ou à doença em vários grupos demográficos. A base teórica que prossibilitou sustenção de analise das evidencias foram filtradas na bases de dados Medline e Pubmed. 


\section{CAMPO DE INVESTIGAÇÃO}

O cenário escolhido para o desenvolvi-

mento deste estudo foi à sede da Empresa de Correios e Telégrafos (ECT) da cidade

\begin{tabular}{|c|c|c|}
\hline & Quantidade & Idade Média \\
\hline Homens & $23(92 \%)$ & 35,70 \\
\hline Mulheres & $2(28 \%)$ & 37,50 \\
\hline Total & 25 & 35,84 \\
\hline
\end{tabular}

Figura 1: Escolaridade dos carteiros do Juazeiro do Norte pesquisados no período de abril e maio de 2009.

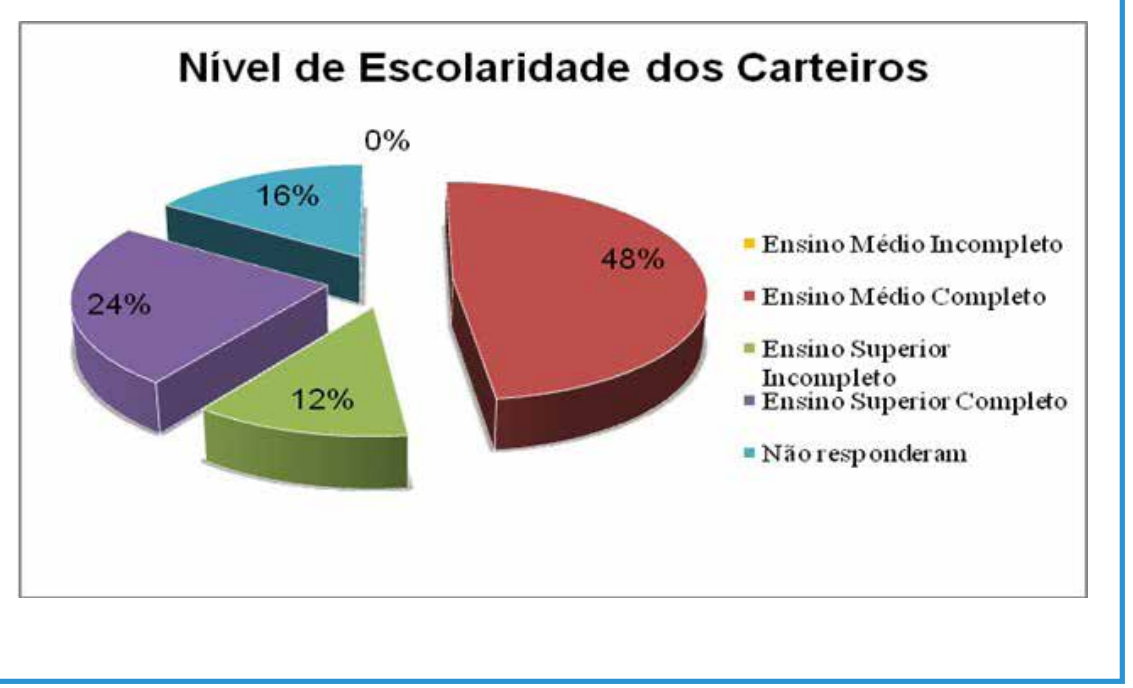

Fonte: Autoria Própria

Figura 2: Distribuição de frequência do tempo, por anos de trabalho dos carteiros de Juazeiro do Norte pesquisados no período de abril e maio de 2009.

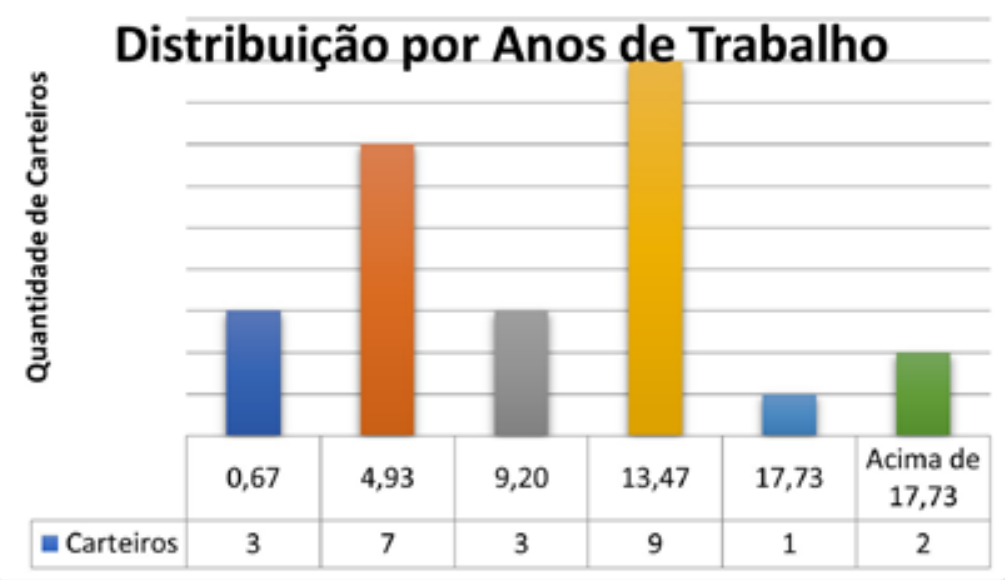

Fonte: Autoria Própria de Juazeiro do Norte- CE, situado na Rua da Conceição, $n^{\circ} 354$, cidade localizada no sul do Estado, a $600 \mathrm{~km}$ da capital, Fortaleza. Sua área é de $248,558 \mathrm{~km}^{2}$, a uma altitude média de 350 metros.

\section{POPULAÇÃO}

A população estudada envolveu todos os carteiros da ECT do Município de Juazeiro do Norte que, no período de realização da coleta de dados da pesquisa, exerciam atividades na instituição, sendo a amostra do tipo intencional composta por um total de 25 carteiros.

\section{ESTRATÉGIAS PARA ANÁLISE DE DADOS}

A análise estatística foi realizada por um profissional dessa área de conhecimento vinculado à Universidade Estadual do Ceará, com a utilização do programa computacional Statistical Package for the Social Sciences (SPSS) versão 13.0.

\section{RESULTADOS}

Participaram da nossa investigação 25 carteiros dos quais 23 eram do sexo masculino e somente 2 eram do sexo feminino, representando 92 e $8 \%$ respectivamente.

Em se tratando, especificamente, da mão de obra, a participação masculina constitui característica ainda marcante dessa profissão, tanto no cenário brasileiro quanto mundial, fato este também evidenciado em nosso estudo.

No que se refere à faixa etária do grupo as idades variaram entre 22 a 49 anos. A média das idades dos 25 carteiros foi calculada em 35,84 anos, para as mulheres (duas profisisonais) essa média foi de 37,50 e para os homens a média aritmética da idade equivale a 35,70. Estas informações podem ser melhor visualizadas na Tabela 1 a seguir.

Em relação ao nível de escolaridade dos sujeitos da pesquisa, constata-se inicialmente, que a quantidade de carteiros com nível de escolaridade "Nível Médio Incompleto" é 0 (zero), o que pode ser explicado pela exigência mínima para ingresso neste cargo é possuir o nível médio completo.

A Figura 1 destaca as proporçôes dos participantes quanto à escolaridade. 
Figura 3: Distribuição do horário de trabalho externo dos carteiros do Juazeiro do Norte pesquisados no período de abril e maio de 2009.

\section{Horário de Trabalho Externo}

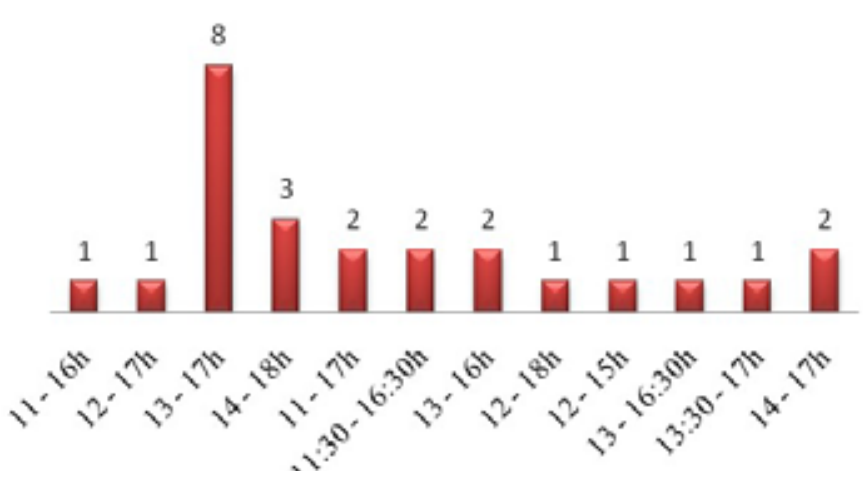

Fonte: Autoria Própria

\section{Figura 4: Identificação do Fototipo cutâneo}

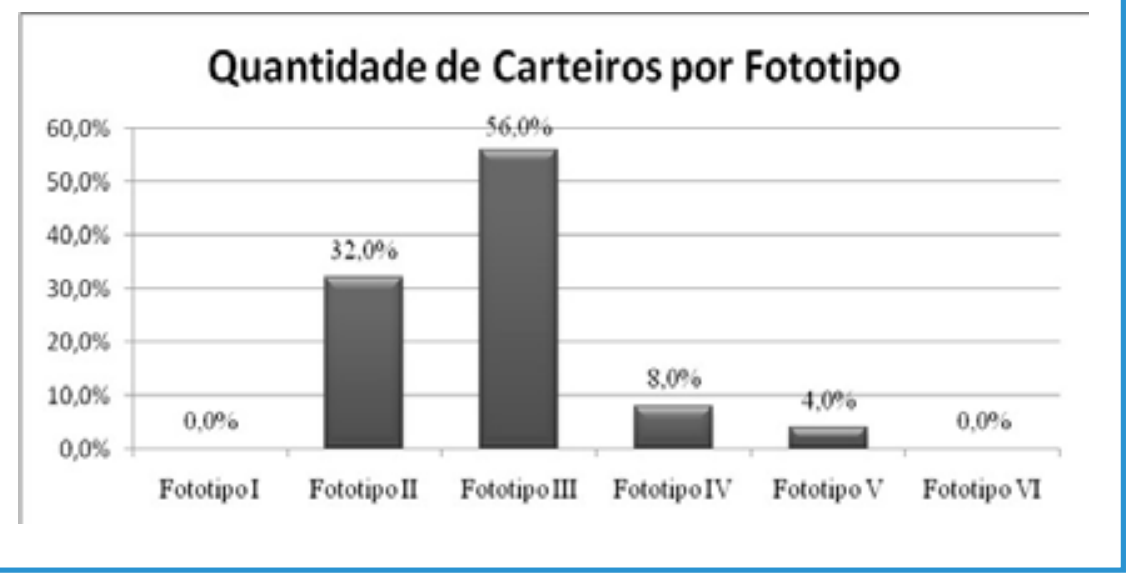

Fonte: Autoria Própria

Figura 5: Comportamento da pele após exposição ao sol dos carteiros do Juazeiro do Norte.

Pele dos carteiros após exposição ao sol

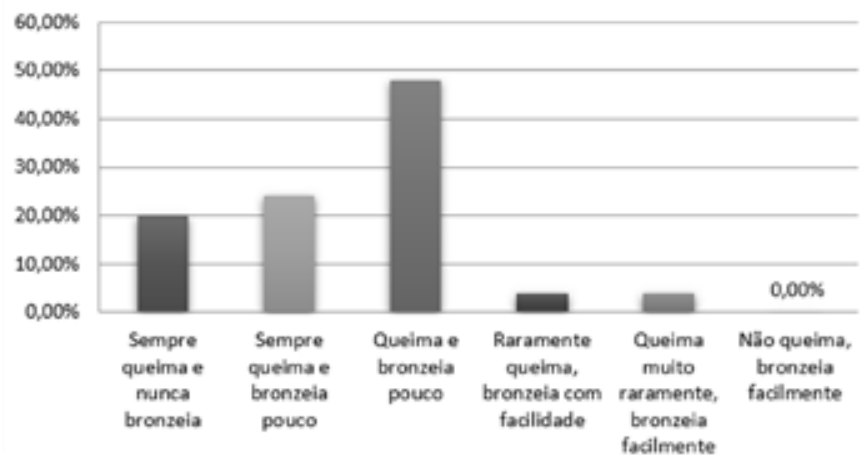

Fonte: Autoria Própria
Ao compararmos o nosso universo de pesquisa com outros trabalhadores que também têm exposição solar, observamos que houve certa redução quanto ao nível de escolaridade.

Em relação ao vínculo empregatício entre os sujeitos analisados, identificamos que em relação a anos de trabalho houve uma variação de um tempo mínimo de 8 meses e um tempo máximo de 22 anos de compromisso com a empresa. Para saber melhor como se distribuem esses dados, a Figura 2 a seguir, mostra o padrão de distribuição, através da ferramenta Histograma com o auxílio da freqüência estatística

Quanto à divisão dos períodos de trabalho, os horários estão divididos em trabalho interno e externo. Pode-se visualizar na Figura 3 os horários de trabalho externo dos carteiros do Juazeiro do Norte.

Podemos observar na Figura 3, em relação ao horário de trabalho externo, que todos os trabalhadores se expoem ao sol em horários indevidos e que a maioria dos entrevistados fazem exposição ao sol por volta das 13:00 às 17:00 horas, período do dia que as radiações UVA e UVB estão mais incidentes, sendo este um horário mais propício para o desenvolvimento de doenças de pele.

A seguir na Figura 4 são apresentados os fototipos dos carteiros.

Para a identificação da ocorrência dos fatores de risco para câncer de pele nos profissionais pesquisados, foi necessário, conhecer como se observa o comportamento da pele dos carteiros quando há exposição ao sol.

$\mathrm{Na}$ Figura 5 são apresentadas as alterações percebidas pelos carteiros de conformidade com os efeitos da exposição ao sol durante a jornada de trabalho.

O Fator de Proteção Solar utilizado por estes profissionais pode ser verificado na Tabela 3 a seguir.

Outro parâmetro que pode auxiliar na avaliação de existência de fatores de risco dentre os fatores fenotípicos para o câncer de pele, é o histórico familiar da população pesquisada. Tal situação está apresentada no gráfico da Figura 6.

No que tange às possíveis relações entre ocupação e fatores de risco para o câncer de pele na população em estudo, 10 car- 
Tabela 3: FPS utilizado pelos dos carteiros do Juazeiro do Norte pesquisados no período de abril e maio de 2009.

Fator de Proteção usado no horário de trabalho

FPS 30

FPS 50

Total

24

Fonte: Dados colhidos através da aplicação do questionário da Pesquisa: "Estudo das atitudes e práticas face à exposição solar dos carteiros do Município de Juazeiro do Norte-CE". (ANEXO - A)

Figura 6: Existência de casos de câncer de pele na família dos carteiros do Juazeiro do Norte pesquisados no período de abril e maio de 2009.

\section{Casos de Câncer de Pele na Família}

Houve $\square$ Nãohouve $\square$ Não informou

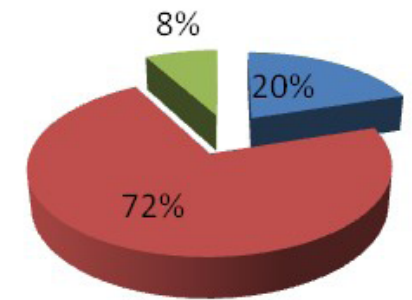

Fonte: Autoria Própria

Tabela 4: Tipo e Local das Lesões identificadas pelos carteiros do Juazeiro

do Norte pesquisados no período de abril e maio de 2009.

$\begin{array}{lc}\text { Local e Descrição } & N^{\circ} \text { de carteiros } \\ \text { Mancha no colo } & 1 \\ \text { Manchas brancas e escuras no pescoço } & 1 \\ \text { Manchas Brancas } & 2 \\ \text { Manchas vermelhas no rosto e no colo } & 1 \\ \text { Feridas na orelha } & 2 \\ \text { Manchas escuras no rosto } & 2 \\ \text { Feridas na testa } & 1 \\ \text { Total } & 10 \\ \text { Fonte:Autoria Própria } & \end{array}$

teiros referiram ter alguma lesão em decorrência do trabalho. Para os profissionais pesquisados que responderam já ter apresentado lesões na pele em decorrência da atividade de Carteiro, foram identificados os seguintes casos, através do questionário de pesquisa, os seguintes casos conforme pode ser verificado na Tabela 4 .

\section{DISCUSSÃO}

A elevada incidência de doenças de pele está relacionada principalmente a exposições realizadas ao sol de forma freqüente e prolongada, seja por meio de atividades recreacionais, estéticas ou profissionais, sendo este último, um grupo constituído por pessoas que possuem uma maior possibilidade de adquirir doenças de pele ${ }^{[6-9]}$. As doenças relacionadas ao trabalho, distintamente, embora não possuam especificidade com determinado tipo de ocupação, apresentam maior incidência em trabalhadores envolvidos em determinadas atividades. Dentre essas atividades que estão relacionadas à exposição solar, podemos destacar os pescadores, agricultores, salva-vidas, guardas de trânsito, garis, carteiros, entre outros.

A população rural em que os homens se expõem ao sol, mais do que 3 horas/ dia, enquanto que as mulheres, até 1 hora/dia, também verificou-se que devido à falta de informação grande quantidade de indivíduos do sexo masculino (79\%) nunca usou filtro solar ${ }^{[1-9]}$. Quanto ao sexo feminino, apesar da maioria saber o que é um fotoprotetor, mais de $50 \%$ das entrevistadas (52\%) também nunca o utilizaram. Isso mostrou que a população da zona rural ainda é carente de informações sobre o assunto ${ }^{[6-12]}$.

Sobre as condições de saúde e risco para doenças crônicas em trabalhadores de uma usina de açúcar e álcool observou-se que em relação às atividades de trabalho cerca de $65,8 \%$ realizavam suas tarefas expostas ao sol e 35,3\% nunca utilizavam proteção solar (incluindo chapéu, camiseta e filtro solar) sendo que $32,7 \%$ utilizavam proteção algumas vezes ${ }^{[10-15]}$.

O sol emite radiações de diversos comprimentos de ondas, o chamado espectro eletromagnético. Pode ser dividida em duas grandes regióes de acordo com a capacidade de ionização atômica: radiação ionizante e radiação não-ionizante. A radiação ionizante, por sua vez, é subdividida em raios-X e raios gama, enquanto a radiação não-ionizante subdivide-se em radiação ultravioleta, luz visível e radiação infravermelha. Felizmente a radiação ionizante altamente prejudicial não penetra na atmosfera terrestre ${ }^{[10-15]}$. 


\section{artigo}

Devido à destruição da camada de ozônio, a incidência de raios UVB, intrinsecamente relacionados ao câncer de pele, vem aumentando progressivamente, permitindo, inclusive, que raios UVC se aproximem mais da atmosfera terrestre. Já a incidência dos raios UVA independe da camada de ozônio e, portanto, causa câncer de pele em indivíduos que se expõem ao sol, sobretudo em horários de alta incidência, continuamente e durante muitos anos ${ }^{[6,7,9,12]}$.

A unidade de medida de uma queimadura solar é a dose eritematógena mínima (DEM), dose capaz de produzir um eritema nitidamente demarcado na área irradiada pela RUV, depois de uma única exposição. Assim como ocorrem variações no espectro da luz solar, a DEM também varia com o sol[13-15].

A DEM, também denominada de eritema de $1^{\circ}$ grau, pode ser usada como dosagem na prescrição da RUV. O eritema de $2^{\circ}$ grau, ou intenso, é causado por uma dose de cerca de duas vezes e meia a dose de um eritema mínimo, apresentando um período de latência de 4 a 6 h e pode ser um pouco dolorosa, regredindo em 2 a 4 dias. É seguido de descamação. O eritema de $3^{\circ}$ grau, ou grave é causado por cerca de cinco doses de um eritema mínimo e apresenta um edema associado. O período de latência pode ser breve, cerca de $2 \mathrm{~h}$ e é seguido por descamação acentuada. $\mathrm{O}$ eritema de $4^{\circ}$ grau é produzido por cerca de 10 DEM e é caracterizado adicionalmente pela formação de vesículas (bolhas superficiais $)^{[1,4,8,10,13]}$.

Dentre os efeitos benéficos da RUV pode ser citado o efeito anti-raquítico, bactericida, germicida e sobre o metabolismo, sendo que após a exposição à RUV ocorre um decréscimo na taxa de açúcar no sangue, quando observada a taxa de excreção urinária de pessoas diabéticas ${ }^{[14,15]}$.

\section{CONCLUSÃO}

Evidenciamos com as informações colhidas e analisadas na pesquisa, que os equipamentos fornecidos pela ECT não são suficientes para suprir as necessidades diárias dos trabalhadores investigados. Encontramos, também, como já foi relatado anteriormente, que apesar da mesma não monitorar a forma de proteção que esses trabalhadores estão realizando, a empresa não incentiva os mesmos a utilizarem a proteção de maneira correta.

No que se refere a fatores de risco para doenças de pele em relação ao histórico familiar, encontramos que a maioria dos carteiros não relata casos de câncer de pele na família. Quanto ao histórico de lesões dos mesmos em relação a exposições pregressas à atividade de carteiro, a maioria informou não existir história de lesões na pele, porém, em relação ao surgimento de lesões em decorrência do trabalho na função de carteiro identificamos que quase a metade dos entrevistados referiu ter alguma lesão em decorrência do trabalho.

\section{REFERÊNCIAS}

1. Bakos, R. M.; Wagner, M. B.; Bakos, L.; Rose, E. H.; Neto. J. A. G. Queimaduras e hábitos solares em um grupo de atletas brasileiros. Rev Bras Med Esporte _ Vol. 12, N 5 - Set/Out, 2006

2. Azulay, R., D.; Azulay, D., R. Dermatologia. 2. ed. Rio de Janeiro: Guanabara Koogan, 1999.

3. Bykov, V. J.; Marcusson, J. A.; Hemmininki, K. Effect of constitutional pigmentation on ultraviolet $\mathrm{B}$-induced DNA damange in fairskinned people. Jounal of Investigative Dermatology. 114; 40-43, 2000

4. Carvalho, K. D.; Alves, R. R. S.;Funghetto, S. S.; Reis, P. E. D. Estratégia de educação em saúde na prevenção do câncer de pele por agentes comunitários de saúde. REEUNI - Revista Eletrônica de Enfermagem do UNIEURO, Brasilia, v.1, n.3, p. 28-41, set/dez, 2008.

5. Chorilli, M; Otto, T.; Alves, M, I. F. A.; Cavallinl, M. E.;Leonardi, G. R. Avaliação do uso de protetores solares pela população rural de Piracicaba-São Paulo-Brasil, através da aplicação de questionário Rev. Bras. Farm., 88(4): 167-172, 2007

6. Costa, F., B.; Weber, M., B.; Avaliação dos hábitos de exposição ao sol e de fotoproteção dos universitários da Região Metropolitana de Porto Alegre, RS. ANAIS. BRASILEIROS DE DERMATOLOGIA, Rio de Janeiro, v.79, n.2, Mar./Abr. 2004. Disponivel em: http://www.scielo.br/scielo.php?script=sci_arttext\&pid=\$036505962004000200003=
7. Dermatoses por Fotossensibilidade. (2018).Disponivel em: http:// www.dermatologia.net/neo/base/artigos/fotossensiveis.htm.

8. Fitzpatrick, T., B.; Johnson, R., A.; Wolf, K.; Polano, M., K.; Suurmond, D. Dermatologia Atlas e texto. 5. ed. Rio de Janeiro: McGraw-Hill, 2006.

9. Guirro, E. C. O.; Guirro, R., R., J. Fisioterapia Dermato-Funcional. 3. ed. São Paulo: Manole, 2002.

10. Filho, V. W. Perfil Epidemiológico dos Trabalhadores. Rev. Bras. Med. Trab., Belo Horizonte. v. 2, n. 2, p. 103-117. Abr-Jun, 2004

11. Gervini, R. L.; Gorelik, M. Fotoproteção.(2017) Disponível em: http: <www.FOTOPROTE\%C7\%30\%20ABC\%20da\%Sa\%...>.

12. Instituto Nacional de Câncer (INCA). Prevenção e detecção. (2018). Disponível em: <http://http://www.inca.gov.br/estimativa/2010/index.asp?link=conteudo_view.asp\&ID=5>.

13. Kirchoff, V.W.J.H. Ozônio e radiação UV-B. São José dos Campos, SP:Transtec, 2015.

14. Langley, R. G.; Sober, A. J. A clinical reviw of the evidence for the role of ultraviolet radiation in the etiology of cutaneous melanoma. Cancer Invest. 15 (6): 561-7, 1997.

15. Martin, R. H. Relationship between risk factors, knowledge and preventive behaviour relevant to skin cancer in general practice patientsin south Australia. Br J Gen Pract. 2015 Jul; 45(396): 365 - 7 